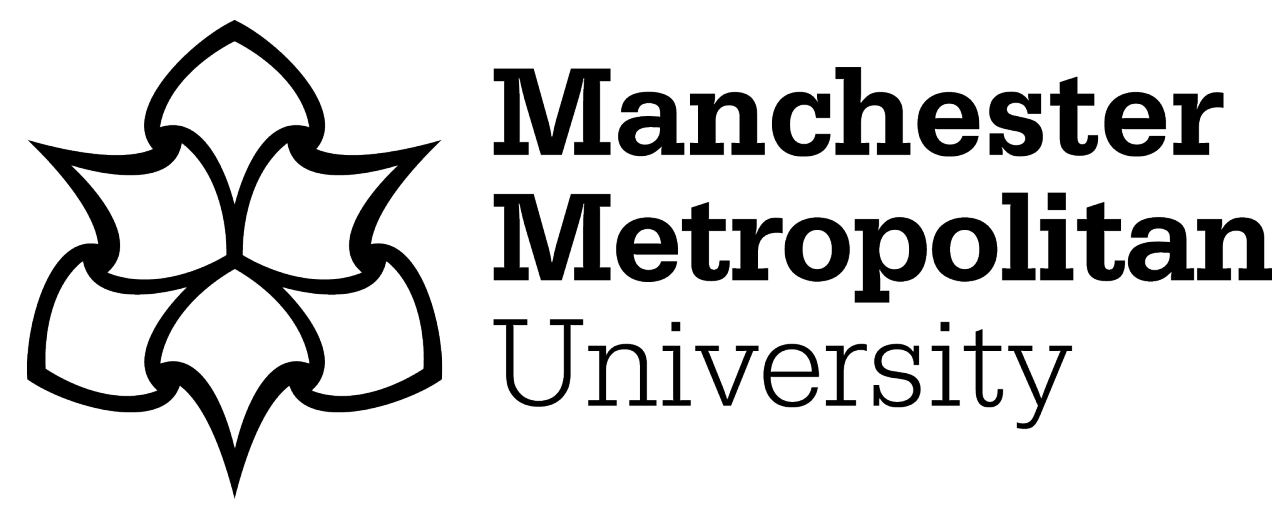

Hartley, CF and Whittle, S (2003) Different sexed and gendered bodies demand different ways of thinking about policy and practice. Practice, 15 (3). pp. 61-73. ISSN 0950-3153

Downloaded from: https://e-space.mmu.ac.uk/621103/

Version: Accepted Version

Publisher: Taylor \& Francis

DOI: https://doi.org/10.1080/09503150308416927

Please cite the published version 


\title{
Different Sexed and Gendered Bodies Demand Different ways of Thinking About Policy and Practice
}

\author{
Practice: A Journal of the British Association of Social Workers, (2003) 15(3) pp. 61-73
}

[3676 words] Christine F Hartley \& Stephen Whittle

\begin{abstract}
We live in an increasingly multi-sexed and gendered society. Social work professionals often are well informed about cultural sensitivities in relation to race, ethnicity and sexual orientation. But is the same true of concepts of sex and gender diversity and the social sensitivities that are involved here? Do social care professionals have the appropriate policies and skills to manage the needs of differently sexed and gendered people? This paper outlines the social emergence of the transgender community, signalling to social care practitioners a need to review existing practices and policies to ensure they are addressing the needs of this diverse community. Attention is drawn to particular difficulties 'trans' people have experienced when drawn into the social care arena. The paper suggests points of reference for reflexive practice that may support practitioners working with this diverse group of people and who are interested in emancipatory practice.
\end{abstract}

\section{Introduction}

If we are committed to creating true multicultural and inclusive practice and are passionate about 'inclusivity' for all, policy and practice should not only be geared to serving the needs of established cultures but the needs of emergent groups. Individuals and diverse communities are beginning to interpret their worlds in terms often referred to as post-modern and are abandoning the normal understandings that construct the world in dualistic ways such as the division between the public and private (Lincoln \& Guba 2000). This is seen clearly in the areas of sex, gender and sexual orientation for those minority groupings where the normative binary structures do not reflect their lived experience.

The transgender community provides a good example of changing social phenomena and presents new challenges for social care professionals. Little work has been done to understand to health and social welfare needs of this minority group, therefore gaps still remain in practice. As society becomes more open and tolerant of different expressions of sex and gender, we need to 
continue to develop practice that is sensitive to issues of diversity and equality and in tune with its changing needs.

\section{The Background to a New Needs Community}

The first sex changes were first performed in the 1950's and now hormonal and surgical reassignments are regularly sought. In recent years, developments have also occurred in 'trans' terminology that shift the emphasis away from 'transsexual' identities that appear to make a clear change from one sex to the other, to 'transgender' identities which amounts to the recognition of a wide diversity of gender expression and gendered bodies (Denny 1995). Consequently we are faced now with a 'trans' community with a wide range of health and social care needs in respect of their sexed and gendered bodies and identity.

It is often presumed that these needs relate only to the physical aspects of gender reassignment and whilst many 'trans' people have been long-term reassigned and are fully adjusted to their new social role, some may not be. Many medical practitioners may now be aware of the physical and surgical issues involved in gender reassignment, as a consequence of providing primary health care, but health and social needs for the transgender community are much more complex and involve the life long needs of maintaining a 'trans' body and aspired gender role (Stephens \& Whittle 2001). Further, only a minority of 'trans' people have long histories of living with reassignment because, since social changes and greater acceptance, we now see far more people confronting their issues of sexed and gendered, ambiguity and difference at all stages in life (Witten \& Cook-Daniels 1999), whereas in the past they pushed these thoughts to the background, and would not have acted upon them because of the associated stigma (Goffman 1968).

Whilst there are no exact figures of how many transsexual people there are in the UK, the Wessex Institute for Health Research and Development (1998) indicated that 5 requests per year for full surgical reassignment could be expected within the South West Region of England. This suggests a statistical prevalence ratio of 0.17 per 100,000 people seeking gender reassignment surgery can be expected across other regions of the UK, in other words 102 per year. This number is undoubtedly an underestimate as Charring Cross Hospital Gender Identity Clinic purports to provide 4 beds each week for the surgical reassignment of (male to female) transsexual women, and it is the experience of one of the authors that whilst undergoing a series of complex 
phalloplasty surgeries in the Middlesex Hospital that at least 3 other trans men are alongside him in the ward. There is also a thriving private health care market in gender reassignment procedures. This numerical difference would arise due to geographical factors, as many trans people migrate to the urban areas where there are strong communities for them to join.

The numbers of trans people in our society has undoubtedly grown in recent years as more people are becoming informed through support groups and Internet communities about the possibilities of living with differently sexed and gendered identities and bodies, in some cases negating the need for surgical intervention. Therefore, it is very likely that social welfare services will at some stage have to make provision for the needs of this emergent community, particularly as those who were previously excluded may well be those who already have significant needs due to age, health, disability or social status.

\section{The Challenges to Social Care}

The great range of information now available from support organisations and the Internet means these individuals are making informed choices and decisions based on the extent that their bodies are able to express different notions of a sexed and gendered identity. If bodies don't match what is in the mind, solutions may be found in full or partial morphological (bodily) reconfiguration. Differing surgical solutions and options are open for 'trans' people, particularly those for whom full gender reassignment surgery would bring its own health risks, and may result in morphological configurations other than what is expected in biologically normative male or female bodies. Whilst many (male to female) transsexual women are successful in achieving full surgical reassignment, it must be acknowledged that some don't (Lord Chancellor's Department, 2002). For medical or other reasons this may not always be achieved fully. Age related conditions such as pulmonary or cardiac problems might disqualify individuals from procedures such as breast augmentation or genital reconstruction. Thus we see the possibility of a fully identified woman with male genitals, or visa versa.

Female to male transsexual men face different challenges and many opt for partial or no genital surgery at all, becoming fully identified men, albeit with vaginas. The fact that the (female to male) body does not conform to normative ideas doesn't make an individual any less of a 'man' or even a 'transsexual' so far as that individual's identity and social relationships are concerned. There may be certain limited medical settings, where the 'femaleness' of the body is an issue, but 
even then it is probably acknowledged by some medical practitioners that, for example, a gynaecological procedure is being performed on a man rather than a woman, albeit a trans man. The transgender community has itself embraced this diversity in the sense that it is now made up of a range of people with differing versions of sexed and gendered bodies.

These new body formats can raise difficult issues for social care practice when sexed and gendered identities and bodies have become composite and at odds with social norms. There are expectations in society of individuals who undergo reassignment to present a clear-cut image of their 'destination' sex and gender. This may not be straightforward. It is recognised that younger people are more successful in developing and presenting normative gendered identities on transition, however older bodies may not be as receptive to change as younger bodies and the process of change for older people may not be as evident. Hormone regimes have varying effects for both trans-men and trans-women. Male hormones (testosterone) do initiate and are usually more effective in quickly sustaining masculine features (Rees 1996) for 'trans-men' than the feminising effect of oestrogen for 'trans-women'. Oestrogens may have little body impact for 'trans-women' and in many cases take a considerable time to reach their maximum potential on the body. For older trans people this may be problematic in the sense that they may never achieve clear-cut representations of 'women' and exist as ambiguously gendered individuals remaining visibly trans. Whilst for many trans people becoming a 'man' or a 'woman' is the ultimate goal, professionals should avoid making the assumption that this is the case for everyone, as many trans people are well aware of the limitations their bodies place on their ability to change and they develop their lives accordingly; perhaps being neither fully 'male' nor fully 'female' (Dana-Tabet 2001).

In supporting the social welfare needs of these communities, professionals need to be aware that people with differently sexed and gendered bodies do exist and have particular needs. The success of social care interventions is conditioned by positive and unconditional regard for the needs of individuals (Banks 2001). Professionals need to be aware of specific issues that affect the lives of trans people. For example, when entering into a care setting it may be the first time that a trans man or woman has had to reveal their body to others for an extended period of time. In every day life genitals are hidden and rarely or never contribute to the way others construct people as sexed and gendered individuals. Genital exposure in care settings therefore takes on different meanings when dealing with trans people. In a recent interview conducted by the first 
author $(\mathrm{CH})$ a trans man expressed his fear of the future about being bathed in a care setting and the possible assumptions that people would make of his genital arrangement and the reactions of care staff to him. He said, 'I would rather 'top' myself than experience that humiliation' (Hartley forthcoming). It is not just genitals that are potentially problematic, for example, anxieties over the daily removal of facial hair in hospital led one 'trans-woman' to risk walking unaided to the toilet after an operation. She said:

I was so anxious I got out of bed at about five o'clock in the morning before people started to move about so that I would have some privacy in the bathroom. It was only after I had done that I could go back to bed and rest properly (Hartley forthcoming).

Although she was suffering from post-operative nausea and fell in the process it was important to her to deal with this issue covertly as a means of protecting her sense of identity and self-esteem. Disclosure for her meant the possibility of being socially stigmatised, being discounted as a woman, and in some circumstances being discounted as a person.

In the most part, social care practitioners who are not specialist in the care of trans people have little knowledge about specialist needs and concerns (Morton, Lewis, Hans and Green 1997). They need to become more aware and sensitised to transsexual and transgender perspectives, issues and circumstances, if they are to provide inclusive quality services. They need to understand that issues of gender identity never challenge most people; their sex and gender is a 'social given'. The subjective experience of being trans spells out sexed and gendered identity as a 'social achievement' (Garfinkel 1967; Kessler \& McKenna 1978; West \& Zimmerman 2002) and in many cases that achievement can remain a vulnerable aspect of a person's identity. Decisions to make adjustments to a gender identity usually are the result of years of mental turmoil and social incongruity and are not arrived at lightly; therefore insensitive approaches are potentially damaging. The investments trans people make in being able to realise their gender identity are immense; the stakes are high. The reality is that little social acceptance is afforded for those that fail, and the effects of failure can be catastrophic both at a social level and a personal level. Trans people are very aware of the pervasive social prejudice and ignorance of society in general, in many cases becoming highly sensitive to trans-phobic intolerance and discriminatory practices, in order to survive (Thomas \& Mason 2001; Witten \& Eyler 1999). 
It is therefore inappropriate for organisations to gloss over their approach to this highly sensitive area of health and welfare provision. Relying on front line staff to apply generic principles of practice and existing interpersonal skills may not be sufficient in these cases and specific policies, which acknowledge the potential complexity of the body, should underpin their practice in this area. A hospital patient who uses a stoma bag will find a staff equipped with bench marks and good practice models to facilitate bodily integrity and respect, a bed bound trans man who needs to sit to urinate will find staff invariably provide a bottle rather than a pan. Each time he has to remind staff his security in his constructed identity is challenged, as he is required to reiterate his difference. The problem lies with the uncritical use of sexed and gendered categories in the development of services and policy issues. Organisations would benefit from a deeper understanding of trans lived experiences and ways of functioning.

It is useful for professionals to be aware that trans people do not always adopt ways of talking that relate to sex and gender in the same way as non-trans people. Whilst it is common for some trans people to talk of changing from one sex to another using expressions such as 'being born in the wrong body', others don't. Some individuals may talk in ways that suggested they reclaim aspects of the self (More \& Whittle 1999) through a 'rites of passage' (Bolin 1988; Van Gennep 1960) and process of change. For example, in describing her experience one 'trans-woman' states.

I just became me.... well they talk about the child within and I suspect that's what I actually revisit, because that's the part of who I became that was missing, if you like (Hartley forthcoming).

The change she described may be understood in a humanist sense, as reclaiming an essence of self that is unique and unitary (Weedon 1997). However, whilst recognising and acknowledging the trans struggle for identity, adopting an approach that is concerned with individual essence is professionally limiting and problematic. According to Bloom (1998):

Claiming the existence of an individual essence in Western humanist ideology denies the possibility of changes in subjectivity over time; masks the critical roles that language, social interactions, and pivotal experiences play in the production of subjectivity; and ignores the multiple subject positions people occupy, which influence the formation of subjectivity (p.3) 
Therefore professionals must be able to 'suspend' hetero-normative thinking that sees sex and gender as stable concepts and learn to consider trans subjectivity on its own terms. 'Trans' identities cannot be considered in a unitary way, we argue it is better to consider them as nonunitary and in a state of flux (Butler 1999; Weedon 1997; Ferguson 1993). By understanding the fluidity and malleability of sexed and gendered identity, the notion of reclaiming a sense of identity or a trans way of talking about being in the world, becomes a plausible concept. Therefore professionals should have an ability to consider the way 'trans' people talk about sex and gender alongside, rather than in opposition, to normative ways. (Rosenau 1992). They should be able to consider 'trans' identities in ways that understand people's subjective experience as being grounded and located in language, produced in everyday gendered, racialised, and cultural social experience. It is important for professionals to understand differences exist in 'trans' talk about sex and gender. When 'trans' people talk for example, about 'becoming me', they are recognising ways of talking about sex and gender that resonate better with their sense of identity. They are responding to shifting social outlooks that are showing signs of being more tolerant of difference. They are bringing out into the social domain knowledge about incongruence with sexed and gendered identities that are socially imposed and assigned, and the 'discord' and 'dissonances' that emerge as a result of that imposition. They are interpreting their difference in ways that make sense to them and talk in ways that reflect how they resonate as individuals and the differences they experience. It is important that professionals remain open to different ways of talking in the social world as they provide useful indicators of the future trajectory of social change.

The voices of 'trans' people are now being heard. Social welfare professionals and policy makers cannot afford to limit their thinking by accepting assumptions about fail to question basic ideas that underpin issues of sex and gender, for example the categories of 'man' and 'woman'. Different ways of thinking about sex and gender are shifting the debate away from biological essentialist notions about the way that sex and gender is constructed toward more progressive ways of coming to terms with the world. Penises and vaginas as determinist are becoming relics of the past because it is not only the shape of our bodies that determine our experience it is the way that we talk about them that is just as important. It would be better to consider the shifts that trans people make regarding their sexed and gendered identity not simply as a lifestyle 
choice, but rather in terms of adjusting the way they are to enable a resonate with their sense of identity in order to make life more comfortable and tolerable for them.

Social work professionals need to be able to adjust their ways of practice that keeps one eye on the changing ways that people talkdiscursive change and the other on their responsibilities to the client or service user, which means approaches to practice must retain a flexibility that is able to respond to social change. At an intellectual level, sex and gender remain highly contested, professionals should not fear the notion of questioning normative ideas about sex and gender and at least be able to translate sexed and gendered difference as a different interpretation of existing categories of 'man' and 'woman'. The danger for 'trans' people is that they become victims of practice that only recognises dualistic notions of sex and gender rendering those who are located in the middle as anomalies. 'Trans' people do not have to be seen as anomalies in the context of language because all representations of sex and gender even hetero normative ways of being sexed and gendered have to make linguistic representations as to how they came to be constituted in the world in the first place. It is within this context that social care practice can become proactive and emancipatory in a way that will embody trans identities into a wider framework of understanding about 'men' and 'women' and 'sex' and 'gender'. A simple start would be the inclusion of specific training as regards the needs of the trans client. The tendency in diversity to training is to generalise an acceptance of difference but not to spell out how that difference should affect practice. Practice in social care settings need clearly to address the changes in care needs of individuals, but there is a further need to ensure that all generic policy, strategy and subsequent practice are trans inclusive. For example adoption assessors are well trained in issues of diversity, but it is the experience of the authors that in adoption applications involving couples where one partner is trans, that routinely the trans status is problematised. Yet research done on trans parents has shown that their children are likely to fare as well as any other child (Green 1978, 1998). Both in social care and health care, the determination of trans inclusive policies would recognise the multi-factoral aspects of the effects of being a trans person; that the process of reassignment is not singular but multiple in its procedures and its consequences; and that the fallout that comes with being trans affects all aspects of the individual's life path. 


\section{Conclusion}

Government initiatives relating to 'trans' issues are now paving the way for new legislation that will mean social care professionals have to become more proactive in emancipatory practice. Following the recent decision of the European Court of Human Rights (Goodwin V UK Government, 2002), which held that transsexual people are entitled to be legally recognised in their new gender role, the UK government intends to legislate making provisions for changes to birth certificates for transsexual people, special provisions in relation to their right to get married, and rights to be treated in their acquired gender (Home Office 2000). It is clear from the draft legislation that genital surgery will not be a major or sole criterion in determining whether someone has legally changed sex or not (Lord Chancellor's Department 2003). Recent dialogue between the government and trans organisations suggests a willingness to have a legislative and administrative process that will, in effect, broaden the way existing categories of 'man' and 'woman' are applied. There is little doubt we shall see legal men with vaginas and legal women with penises.

As a result of this intended change, it is important to consider how to avoid workplace dilemmas arising from the presence of ambiguously sexed and gendered service users. Social care professionals need to evaluate how appropriate their everyday practice would be in dealing with sexed and gendered difference. Practitioners need to ask themselves if their approach to practice is comprehensive in the sense that they are able to accept different expressions of sex and gender at face value and remain neutral. Would practitioners regard a child exhibiting malefemale tendencies as a 'boy with mental problems' or in contrast 'a girl with physical problems'? (Conway 2003). Will a 'man with a vagina' or, a 'woman with a penis' present problems for professionals in the way they practice and operate? Confronting and reflecting on these issues prior to any future developments would be useful not only in the interest of good service provision, but also for the protection of the well-being of the client.

As previously stated 'trans people' in many cases are just as much aware of their 'trans' visibility and difference as professionals may be. Whilst ostensibly they may be oblivious to the reactions of others, often the reality is they are well aware of what goes on around them, and the success of the working relationship between the 'trans' person and professional may hinge on these initial responses. When considering the notion of emancipatory practice, professionals should reflect on the 'trans' experience and consider the very basic assumptions that underpin their 
practice in this area. Questioning the realities of the categories of 'man' and 'woman' provides a starting place for reflection that is, we would argue, second to none. Policy maker's should consider the experiences of professionals adopting emancipatory practices and translate government directives in ways that leave space for creative practice and different ways of talking.

\section{References}

Banks, S. (2001) Ethics and Values in Social Work, 2 edn, Palgrave, London.

Bloom, L. R. (1998) Under The Sign of Hope, State University of New York Press, Albany.

Bolin, A. (1988) In Search of Eve: Transsexual Rites of Passage, Bergin \& Garvey, New York.

Butler, J. (1999) Gender Trouble: Feminism and the Subversion of Identity Blackwell, New York.

Conway, L. (2003) An investigative report into the publication of J.Michael Bailey's book on transsexualism by the National Academies.

http://www.eecs.umich.edu/people/conway/TS/LynnsReview of BaileysBook.html [accessed 234-2003].

Dana-Tabet, A. (2001) "Making the Transgenderist: The Construction of Gender Identity in Boston and Amsterdam" in Haynes, F. \& McKenna,T. (eds.) Unseen Genders: Beyond the Binaries, Peter Lang Publishing, New York.

Denny,D. (1995) The Paradigm Shift is Here, Aegis News, 4:1

Ferguson, K. (1993) The man question: Visions of subjectivity in feminist theory University of California Press, Berkeley.

Garfinkel, H. (1967) "Passing and The Managed Achievement of Sex Status in an 'Inter-Sexed' Person," in Studies in Ethnomethodology, Englewood Cliffs NJ Prentice-Hall, , pp. 116-185.

Goffman, E. (1959) The Presentation of Self in Everyday Life, Penguin, Harmondsworth.

Goffman, E. (1968) Stigma: Notes on the Management of a Spoilt Identity Penguin, Harmondsworth.

Green, R. (1978) Sexual Identity Of 37 Children Raised By Homosexual Or Transsexual Parents, American Jnl of Psychiatry, 135, 6. pp 692-697

Green, R. (1998) Transsexual's Children, International Journal of Transgenderism, Vol 2, No 4, http://www.symposion.com/ijt/ijtc0601.htm

Hartley,C.F. (Forthcoming) Field notes of PhD Thesis, Preston: University of Central Lancashire Home Office (2000) Report of the Interdepartmental Working Group on Transsexual People 226/2000. http://www.homeoffice.gov.uk/ccpd/wgtrans.pdf [accessed 21/08/02]

Kessler, S. \& McKenna, W. (1978) Gender: An Ethnomethodological Approach, Wiley, New York. 
Lincoln, Y.S. \& Guba, E.G. (2000) Paradigmatic Controversies Contradictions, and Emerging Confluences, in Denzin, N. \& Lincoln, Y.S. (eds.) Handbook of Qualitative Research $2^{\text {nd }}$ edn, Sage, London

Lord Chancellor's Department, (2002) Government Policy Concerning Transsexual People, http://www.Icd.gov.uk/constitution/transex/policy.htm

Lord Chancellor's Department, July (2003) Draft Gender Recognition Bill, London: HMSO

More, K. \& Whittle, S. (1999) Reclaiming Genders: Transsexual Grammars at the Fin de Siecle, Cassell, London.

Morton, S., Lewis, Y., Hans, A., \& Green, J. (1997) FTM 101: The invisible transsexual, San Francisco CA 94103: FTM International, Inc, 1360 Mission Street, Suite 200.

Ref Type: Generic

Rees, M. (1996) Becoming a man: The personal account of a female to male transsexual, in R. Ekins \& D. King, (eds). Blending Genders: Social Aspects of Cross-dressing and Sex-changing, Routledge, London, pp. 27-38.

Rosenau, P. M. (1992) Post-Modernism and the Social Sciences: Insights, inroads, and intrusions Princeton University Press, Princeton, NJ.

Stephens, P., Whittle, S. (2001) A Pilot Study of Provision for Transsexual and Transgender People in The Criminal Justice System, and the Information Needs of their Probation Officers. Report for the Home Office, Manchester Metropolitan University: School of Law

Thomas, S., Mason, G. (2001) Engendering Homophobia: Violence, Sexuality and Gender Conformity. British Journal of Sociology 37: 257-273

Van Gennep, A. (1960) The Rites of Passage (trans.by Vizedom, M.D. \& Cassee, G.L.) Routledge \& Kegan Paul, London.

Weedon, C. (1997) Feminist Practice and Poststructuralist Theory, 2 edn, Blackwell, Oxford.

Wessex Institute for Health Research and Development (1998) Surgical Gender Reassignment for Male to Female Transsexual People Development and Evaluation Committee Report Number 88. [available at http://www.epi.bris.ac.uk/rd]

West, C. \& Zimmerman, D. H. (2002) "Doing Gender," in S. Jackson \& S. Scott, (eds.) Gender: A Sociological Reader, Routledge, London.

Witten, T., Cook-Daniels. L. (1999) "Transgender Aging: Introduction to an Emerging Field". Gerontologist 39: 79-81

Witten, T., Eyler, E.A. (1999) "Hate Crimes and Violence Against the Transgendered". Peace Review 11: 461-469 